\title{
Possible actions detached from the formation of the other: culture from the framework of education
}

\begin{abstract}
This article deals with the cultural dynamics that are amplified with education, generating epistemological detachments that give rise to some beliefs which are assumed according to the cultural references of a determined location that assure the production and reproduction of perceptions that someone has about others; where the issue is the recognition of cultural diversity, the forms and ways of being named according to a place of annunciation that is anchored in the ethnic. The results presented in this paper will allow us to understand the link between local culture as well as the forms and ways of naming and representing them as The Other. This is because the representation of different cultures within a given society is controlled by mainstream groups with greater political power and under their points of view. In this sense, the objective is to be flexible and explore the significance of experience rather than through cultural content that is portrayed in the school as a methodological possibility, all in relation to reflexivity. As a result, the article presents descriptions of situations in schools and we conclude by showing the role of culture and The Other in the educational process.
\end{abstract}

Keywords: culture, the other, representation, education, context
Volume 4 Issue $6-2019$

\author{
Wilmer Villa,' Ernell Villa ${ }^{2}$ \\ 'Professor, Faculty of Education, District University Francisco \\ José de Caldas, Colombia \\ ${ }^{2}$ Professor, department of Intercultural and Educational Studies, \\ Guajira University, Colombia
}

Correspondence: Wilmer Villa, Professor, Faculty of Education, District University Francisco José de Caldas, Colombia, Email villa@hotmail.com

Received: September 30, 2019 | Published: November 21, 2019
Pedagogy occurs wherever knowledge is produced, wherever culture is given the possibility of transferring experience and the ability to construct truths, even when such truths seem inexorably redundant, superficial and common sense.

\section{Reflecting on discursive detachments}

Culture from the limits accompanying the actions in the creation of educational proposals, has much to do with the situated knowledge $e^{l}$ and the issue of the subjectivity of the investigator. In this case the actor $^{2}$ is who has a situated knowledge within him/her and their environment; the actor has an active part in the production and should be the one who transforms knowledge. The idea is to change the conventional way that considered the actor only as objects of study applying the contents that the experts deployed on the humanity of The Other. What is presented here is a perception guided by the theoretical frameworks of the disciplines. Contrary to this, we propose to distance ourselves from the usual ways of seeing people, where normally one person (expert, researcher or investigator) speaks for The Other, supplanting their voices which accompany the people in their contexts of their own experiences. Usually what happens is that The Other is represented in the absence of his/her own voice and the absence of his/her own experiences, but above all considering that as legitimate in the study of The Other, there are not self-perceptions, or narratives embodied in their own experiences, but the authorized voice

\footnotetext{
${ }^{1}$ Feminist theory from the movements of black women and Chicanos in the USA, introducing the notion of the 'situated knowledge' and the 'situated imagination' believing that knowledge is in a place and therefore knowledge corresponds to the people of that place more than to the researchers who interpret the assumed knowledge.

${ }^{2}$ People in the community subject to the investigation, participants and members as social actors of a particular place.
}

of those who establish the formation of those who are re-created in the distance that makes a big difference. On the contrary, we adopt the position where actions are generated in the limits creating interactions between cultures and this must be propitiated as an instance of critical reflection, suggesting and transforming not only for those who observe from an external interest, but also for those who act in a context of approximation and negotiation of contents which is significant at the moment of "being together", propitiating connections that trap us here and there. This is understood as the generation of possibilities that enrich and act in the fact of facing problems from the contexts and not on the contexts.

In this paper culture is assumed as part of construction from people's lives in their contexts of interaction and not as an instrumental reduction, made by the dominant groups to express their version on culture. In this respect, what prevails from a standpoint of conventional anthropology is traditionalism, where we seek the rare or the exotic, establishing a scheme of differentiation between "them and us." Similarly, there has been a process of folklorization, which assumes The Other as a spectacle offered and an expression of the different. Multicultural positions are also presented, where the identities and the cultures of the subordinate groups are assumed from recognition, celebrated as part of the diversity that they have, therefore this does not allow to confront and to transform their inequalities it could potentially serve as a means for stigmatization.

The invitation we made in the content of this document is to take seriously the rejected, the voiceless and the one who has been denigrated in order to consider culture "as an essential tool for the fabrication of alterability". ${ }^{1}$ This corresponds to a strategic perspective where the oppressed or the condemned, "use their physical or cultural characteristics to create groups and social categories that allow them to introduce processes of inclusion and exclusion", ${ }^{2}$ it is about 
considering culture as part of a political strategy. "In this way, culture appears as the antithesis of a colonialist project as communities use it as a tool to regain control of their own destiny". ${ }^{1}$ To consider culture within the education framework, we must review the representation practices where the play is usually presented in the same way over and over in a scenario that appropriates the content of The Others. This is how the observer becomes the bearer of legitimate languages with which they represent The Other; this is done from a process of intervention on what initially is presented by investigators and their point of view. Consequently, the actors are diminished, that is to say that at this point they happen to be only subjects-objects of a predominant arrangement, which is operated and positioned at the whim of those who control the symbolic production. We want to promote the fact that the researcher should limit him/her interpretation to the feelings of the people of the communities they are investigating.

For what is exposed in the previous paragraph, we see the need to carry out the detachments of the explanatory frameworks that stabilize the realities to a single reality, where what predominates is only one way of seeing the culture. Therefore, it is not convenient to continue with the schemes of configuration of cultural contents, resulting from the absolute actions of classification, fragmentation and definition of properties that should be promoted as the distinctive of others. From the established by classification schemes and definition of The Other, the imagination from investigators appears as part of an arbitrary act, an act of impersonation and generation of silences. In case, if produced by those who control the re-presentation, who have no right to speak from their realities, but are constantly produced by the saying and acting of the elites. Here, dominant sectors are those who establish the conditions and contents of discourse, which happen to be fixed in public spaces, becoming representative of what people say, do, think, feel, imagine and project in their everyday practices. In this regard, we can take back what Paulo Freire said: Human existence cannot be Silent, nor can it be nourished by false words, but only by true words, with which men and women transform the world. To exist, humanly, is to name the world, to change it. Once named, the world in its turn reappears to the names as a problem and requires of them a new naming. Human beings are not built in silence, but in word, in work, in action-reflection. ${ }^{3}$ If what Paulo Freire said is not fulfilled in everyday practices, then what we have is the making of a deferred being, a being deferred from any possibility of constituting its residence in itself and in being with others. Producing the removal of those incessantly seeking approval from others outside is their being, by the person or persons who control the production of the discourse that generate voluntary and involuntary adhesion. This is the assimilation to cultural schemes of common acceptance in public and private spaces. This happens with "the oppressed" or "the condemned", which do not have and cultivate referents of resistance. Faced with this annulment operation, we must bear in mind the statements made by Jesús Martín-Barbero, who reminds us of the "Pedagogy of the Oppressed", when he returns to address "a culture of silence"4 "Paulo Freire calls the culture of silence the set of patterns of action and schemes of thought that shape the mentality and behavior of Latin Americans". ${ }^{4}$

From a reference view "a culture of silence", generates historical aphonia, where the learned words are part of the colonial heritage, which we find difficult to overcome in everyday life or perhaps we are accustomed to them, presently we cannot or are almost prevented from confronting and transforming those conditions that generate resignation. "But while to say the true word - which is work, which is praxis - is to transform the world, saying that word is not the privilege of some few persons, but the right of everyone. Consequently, no one can say a true word alone- or can she say it for another, in a prescriptive act which robs others of their words". ${ }^{3}$ Actions related with the "awareness" and "transformation", are not from the decision and management process, a person takes above the community, nor from a chosen one who illuminates the path in where people must go, precisely it is a participation, an agreement, a generation of alternatives of change and not the imposition of someone who defines and pronounces "true words". What is important to generate these emergencies are "encounters", a key ingredient for facing the possible actions in the context such as community, school, family, city, political organization, neighbourhood association, all assumed as generators of possibilities of affectation and disposition for the change from the praxis that conjugates wills and disposes of the action.

\section{The culture of silence and representation as a process of invention ${ }^{3}$}

The culture of silence that Paulo Freire addressed is established from the controls exerted by elites on social thought. We see that this is established through directed representations that are comparable with what Stuart Hall calls his "work of representation" as "intentional representation", where "it is the speaker, the author, who imposes his unique meaning on the world through language. Words mean what the author intends to mean". The "speaker" in this case is who represents the hidden programmatic of the dominant sectors that intervene with populations. When addressing the dynamics of subalternization, we find that the "speaker" comes to be who advocates the right to speak on behalf of everyone grouped under the label of "us." This is a discursive strategy to create an effect of belonging to a community or a mass that must be "driven" by those who "delegate" or "choose" as the representatives. It is the "speaker" who, from an "intentional representation", and positions generates at the same time the silence of the others.

The "we" is reduced to a strategy of intervention on the reality of the others, who happen to make assumed as simple "gregarious", "passive" beings, companions of an "acephalous mass", this is why the participation of the "speaker", is supposedly required, and whom appears disguised as leader, spokesman or representatives of the community. In arriving at this part of the development of this text, we cannot leave aside the quotation made by Gayatri Chakravorty Spivak, on the subject of Karl Marx's "Eighteenth Brumaire," where he maintains: "They cannot represent themselves: they must be represented ...", ${ }^{6}$ as it must be revised in the light of an education that prepares for a critical spirit, contributing to the construction and consolidation of a political culture In communities. As a result of "intentional representation", we have the "imposition" of a way of assuming and understanding things, where everything is generated from a circle of articulation of contents that are central in the exercise of assigning and fixing the Cultural meanings that people assume and become naturalized in their daily lives. An example that helps us to understand this is presented in the Colombian context, with the belief that culture must be the vehicle that supports a state of mind, typical of Colombians. This can be appreciated when you approach the experiences of fairs and festivals that are held in the country, where culture is almost always appealed to as a form of expression

${ }^{3}$ A process by which researchers dare to think in place of the individuals they are investigating 
of joy. "Culture is a spree of joy, festivity and color." In this frequent way of alluding to culture, we want to ask the following questions, which are not going to be answered, but are open for reflection: From where does the idea "culture is a spree of joy, festivity and color" come from? And to whom does it represent the meaning that "culture is a spree of joy, festivity and color"?

What is presented with the saying of culture from the belief that this is a spree of joy, festivity and color, "is a way of stabilizing realities to a reality directed to consumption, where the state of "joy" overflows or surpasses any historical, political, economic and cultural circumstance? The "joy" of the party that is typical of culture (supposedly) "infects us all alike", but we must remember that in the festivals and festivities in Colombia as well as in Latin America, who enjoy and lives it is who has the possibility of facing the days of "spree", "joy" and "colourful" from the logic of having capital and means. We cannot forget that in some cases, the overflowing spirit that is created through the spirit of the parties, fairs and festivals, is part of an effect of "a culture of silence", In addition to "a cultural simulacrum", which according to Jean Baudrillard, "the simulation does not correspond to a territory, a reference, a substance, but it is the generation by the models of something real without origin or reality". ${ }^{7}$ The "culture of the simulacrum" acts from the non-response to the process of rooting peoples, it is more the appearance, where everything is led to a state of deception so that everything seems to be okay, when in reality things are different. Nothing is taken into account because the "ethical nation" works in favour of stabilization. During parties, fairs and festivals, integration takes place, where many times, everyone seems to be the same, at least during the euphoria that mobilizes people. There is at that time when we are all "happy", "cheerful", "partygoers" and "colourful". It is the construction of an artificial environment, put to work to maintain a production of meanings, this would correspond to the "intentional representation", which from a referent positions, guides and orientate the production of the meaning from within cultural practices are assumed.

We cannot forget that for a long time we have been presented with mechanisms that direct the production of culture from a referent of acceptance of the patterns of dominant structures, Where the important issue is the subjectivity of those who are outside of these structures, and outside of those who are the actors who must be integrated into a level of material and symbolic production. In this regard, it is necessary to refer to what Víctor Vich has expressed: Thus, in the last years from the academy, much of the "cultural" methods of instruction have been denounced, which are now finally understood as forms of discipline through which naturally "uneducated" and "spontaneous" individuals must self-control their Passions on the way to being constituted as civilized, rational and supposedly "moral" beings ${ }^{8}$ So far the content developed in this text, leads us to identify four ways of assuming culture, which can be related and stress with reality. In this order of ideas, we have the first referring to culture as a construction that people stage; The second would be culture as an instrument used to stabilize the reality of the oppressed; The third is the culture understood as a positioning strategy from within and from below; And the fourth corresponding to "methods of instruction", that is, culture as a way to compensate those who do not possess that culture. Although the four ways of assuming culture are presented in the school setting, the last one is the most frequent in education and school.

\footnotetext{
${ }^{4}$ This phrase has become recurrent, and we usually listen to it in the different places of the country, where we have been observing the celebrations that take place.
}

Culture as a way of compensating (supposedly) "those who do not own it", is related to an illustrated or literate idea of the same, based on the incidence of this referent in the ways of developing school processes, hence this is supported in the approaches of "the deficit theory" developed by the British sociologist Basil Bernstein, who faces culture from the processes of socialization. In this case, "level of education" and "social class" arrives, where the language or restricted codes ${ }^{5}$ and the elaborated codes ${ }^{6}$ are made present according to the social location of the people. Here codes are assumed as "modes or patterns of communication developed during the process of socialization". ${ }^{9}$ Under this consideration, it would be education and the school that makes possible the acquisition of a culture that compensates the people who are marginalized. The formulation that supports the "theory of deficit", roughly speaking, is that "people are deficient and have in school the opportunity to overcome the deficiencies that are characteristic of their social class." "cultural methods of instruction" have been designed, which would "compensate for the students' shortcomings". Faced with the ways of assuming culture within the framework of education, it is necessary to overcome the conventional forms that come from the formulations folklore, where disciplines such as history, anthropology, pedagogy, linguistics, psychology and sociology, have entailed establishing a form of confinement of the customs and traditions of the others. This is evident saying that they are detached from the analytical frameworks, corresponding to the epistemological foundation of knowledge that leaves out the realities faced by peoples, nations, communities and groups. For this reason, today it is thought that talking about culture in education and in school setting, it is not for pedagogues, who are agents specialized in other disciplines, and who have the last word of what is culture.

The development supporting the explanation and justification of culture within the framework of education, starts with a legitimized action through the ways of saying that are part of the prestige of disciplinary knowledge, which precede the knowledge of contexts of interactions; this dynamics, characteristic of the production and circulation of declarative knowledge, is based on discursive contents that are sent on the reality of people who are collected, condemned, absolved, visibilized, invisibilized, possessed or emptied of discursive contents because in the light of the specialist are abnormal, deficient, dysfunctional, inappropriate, incorrect and irregular, among others, is the experience of people placed at the risk of approval or disapproval of the specialized agent of modernity. The specialized agent of modernity is the actor of disciplinary discourse who legitimizes, supervises and controls the production of knowledge, within an organization and institutionalization that are shared by the scientific communities; is the actor who invents and adapts the behaviors of others to the way they see the world of them. In this case two ways of representing The Other from a predominant perspective is made evident. "One is to deny or

${ }^{5}$ These would predominate in the popular classes, that is workers, informal
merchants, migrants and people who do not belong to the mainstream culture, that is to say the monoculture that establishes mechanisms of distinction.

${ }^{6}$ They are part of the middle class and are characterized by being part of the customs and customs accepted as representative of the "cultured" people.

${ }^{7}$ This has been debated in the developments of sociolinguistics, especially since the work of William Labov, who did research on English used by AfricanAmerican children; he took into account aspects of the culture of people with the one that carried out its investigation. These aspects were not considered by Bernstein because of his Marxist inclination instead he focused on aspects of social and economic structuring central to the relationship with the "level of education" and "social class". 
ignore cultural distance, to assimilate others to ourselves or to our neighbours, through the use of analogy, whether the use of the latter is conscious or unconscious. The other is seen as the reflection of the self ".${ }^{10}$ It is the reduction of cultural differences to the understanding of the self that represents the center in the construction of the ways of saying put to circulate on the others."It is the analogy that makes the exotic intelligible, which domesticates."

The Other as an extension of self only exists as long as it is perceived from the familiar, from the forms of habituation or naturalization of the customs that are wanted or are found in the other, it does not matter that the question of adapting to the other is an act of violence, of silencing or invisibilization of what is really human. According to Peter Burke, the second way of representing the others has to do with invention. "It consists in the conscious or unconscious invention of another culture opposed to one's own. In this way, we become "others" to our fellow beings "who are seen in the distance as strange beings that are not part of us, but are part of the others recreated through the discursive constructions that they make.

\section{Who is represented by whom? The essence and need to speak from within considering our roots}

The place of enunciation for social actors who have been marginalized and exploited has played a decisive role in the processes of positioning their content and programmatic reacting to the tyranny of hegemonic power, which internally and externally affects peoples, nations, communities and groups facing the historical development from a crucial fact that affirm their culture. But also, the place of enunciation of these fringes populations has been taken by postcolonial discourses and feminist theories ${ }^{8}$, which are developed in the academic world. In Latin America, part of the cultural studies taking place in this part of the world have been responsible for addressing the place of enunciation from coloniality trajectories and possibilities arriving with decolonization; from the struggles of indigenous peoples, Afros or movements of black communities, peasants, excluded and exploited women's movements in urban and rural contexts, among others. In cases, postcolonial discourses and feminist theories, as well as the cultural studies that are affirmed in the decolonization, a bridge has been established between the political demands and the epistemological approaches. This can be related to what Catherine Walsh point out about Stuart Hall, one of the pioneers in social studies, who maintained "political movements produce theoretical movements", ${ }^{11}$ that is to say that the militancy of the social factors that are manifested in a political way, also generate knowledge that help them with the struggles these fights generate. "It is a longterm practice, aimed both at pointing to the problem, advancing its analysis and understanding, and promoting the necessary processes of learning and intervention"11

When it comes to culture, the possibility of mobilizing the political and the epistemological is an issue as important as representation, which is thought of as the "(...) subject of who speaks, under what circumstances, by whom, and how knowledge is constructed and

\footnotetext{
${ }^{8}$ The feminist theories that we have in mind are those that have to do with the black women's movement, Chicana women, who have developed a series of discussions that mean transformations, especially in the United States of America, where the debate of actions Affirmative, as well as the debate of the historical debts of the national states, have had a strong incidence, especially after the decade of the 60 with the fight of the civil rights.
}

translated within and between different collectivity's located within asymmetric relations of power. In addition, there is the important question of how identity itself is constituted and what are the conditions that make human action possible? ${ }^{12}$ This happens through the politics of location, typical of postcolonial discourses and feminist epistemology, as well as cultural decolonial studies, where Edward said, "We learned that what is important is not what is said, but where it is said;" for example the forms of representation that were made from the orientalist studies in charge of making an invention from Europe about the Orientals of the Middle East. In this case the place of enunciation would not correspond to the Orientals but to the Europeans, this would make a problem that has been faced from the question: Who represents who? Could European researchers in this case know what it really means to be an Oriental?

Although postcolonial discourses and feminist epistemology are supported on different foundations, as in decolonial cultural studies, the question that allows us to make a relation of affectation and exchange of critical contents is the emergency discursive where the historical conditions of production of knowledge are taken into consideration. Here we have that the origin, the structuring, the formalization, the monopoly, the circulation and the distribution of knowledge, depends on "geopolitics of knowledge", This is the center-periphery relationship, as well as the possibilities that emerge from the Global South ${ }^{10}$, where "dialogue must be given among critics who live different types of oppressions in different parts of the world, in intercultural dialogue in this case is not with The privileged, but with the oppressed intellectuals who recreate their own culture and also the modernized global culture"11

In considering the place of enunciation with respect to "the geopolitics of knowledge," the problem of the asymmetric relations of hegemonic power is exposed, which has led to ignore or overlook the actors, the stages and the constructions or elaborations derived from these relations that give privilege to the productions of certain places in the world, while others are left behind, in other words they are victims of an "epistemological blindness", according to Boaventura De Sousa Santo, ${ }^{14}$ because "an adequate (experiential) attitude is necessary"14 thereby achieving the "mythification" of science and passing "more to the emancipatory". The "epistemological blindness" has led to what the Colombian anthropologist Nina de Friedemann called "academic invisibility," which appears "as a strategy of domination" that has been projected in time and space over almost five Centuries and has succeeded in shaping various spheres of science and politics"15 The question of the place of enunciation, while the constitution of the "agencies" that determine the production and circulation of the discourses that are underpinned by a "previous regime of authority,"

${ }^{9}$ Geopolitics of knowledge "refer simultaneously to two opposing but also related processes. On the one hand, geopolitics of knowledge constitute an imperial design, on the other hand, the project of epistemic decolonization (...) articulates in a critical way the colonial design and its legacies in the present, taking as conceptual axis the current local history (...) and the relationship between these local histories and global designs".

${ }^{10}$ It should be noted that the Global South breaks with the "center-periphery" relationship, as Professor Walter Mignolo has pointed out, "the center has a south, as the south has a center", meaning that the relationship ends production, supported by a geographic determinism and establishes a situation of complex production.

${ }^{11}$ Enrique Dussel. Seminar Political Philosophy in Latin America Today. Quito. Doctorate in Latin American Cultural Studies. Universidad Andina Simón Bolívar, headquarters Quito-Ecuador, summers of 2009. 
leads us to take seriously the role played by the actors and authors, where the question appears: In whose name is it spoken? This is the problem of representation. In view of this, it is important to keep in mind that, "what define the new fields are the locus of enunciation rather than the configurations of the enunciated". ${ }^{16}$ This is about raising awareness about the dynamics of action that leaves people out who are represented from the specific contexts, and are being supplanted by abstract ways of communication representing universal general concepts. Is the situation and need to talk to somebody and from a place...? Arriving in this way to replace the regular ways of speaking or saying in, by, why, and who about authors who are in permanent absence because they are not those who are represented through what is spoken or said, there is evidence of a point of generalized fugue where writing becomes a "tool of appropriation" of the realities and contexts of the actors, is the disconnection of "who speaks (in the story) is not who writes (in life), and who writes Is not who exists." ${ }^{17}$

The fact of speaking with . . . and from a ... has as a purpose to move away from absolutism as a form of theoretical generalization characterized in the discourses shaped by modernity, seen as a project of expansion and universal dissemination of values and features, a way of seeing and demanding the human from the project of "Westerneuro" humanization. Speaking with. . . and from. .., is narrated from a situated action, where the first refers to the actors, while the second, refers to the location, let us not to lose sight of the people who generate the action, always doing it from a place or a specific context, where we consider, "who speaks" and "who writes", it does so from a position that comes to reflect origin, formation or constitution, as well as the distance by which the actors has past. For this reason, we cannot ignore "and should recognize that we all speak from a particular place, from a particular history, from a particular experience, in a particular culture..." ${ }^{5}$ Undoubtedly, the idea is to take new forms of mentioning others seriously by practicing the policy of production of knowledge, related to the dynamics of writing in the center of the discussion of silences and obliterations in which the subaltern groups have been subjugated. As we have said, this is a possibility for generating incarnated narratives with possibilities of creation of comprehensives actions between nations, towns, communities and groups representing themselves as producers of knowledge. Hence, we cannot forget or leave aside the co-creation, the affectation-affected that mobilizes and displaces the actors from the safe place usually adopted by the experts. It is the feeling that overflows and invites participation, collaboration and cooperation. Consent is with those who participate to learn and learn to participate in relation to themselves and others. It is not about the "epistemology of the individual cognitive ", but also the "epistemology of the recognized individual as ", as Irene Vasilachis de Gialdino points out, she approaches these two epistemologies, getting to differentiate them, showing the possibilities that are generated with the second theory. In this respect she states: On the contrary, the Epistemology of the known subject comes to speak where the Epistemology of the cognoscent subject is silent, mutilates or limits, and intent that voice of the known subject does not disappear behind of the cognoscent subject, or is distorted as a consequence of necessity to translate it according to the codes of the ways of knowing that are socially legitimized. ${ }^{18}$

What is involved in the situation of acting with... and from.., is the need to remove subjects from the closures they suffer when they blindly affirm and defend what constitutes the Fastened-subject to the cultural structure, as well as Fastened-subject to a specialized narration of science or also as a Fastened-subject to a religious dogma.
This propitiates an imperceptibility of the experiences that enable the emergencies from other temporalities, spatialities, experiences and generation of texts that come to enrich the encounters and affectations between the cultures. One thing that is sought with the generation of possibilities interpreted as part of emergencies is to bring the absent actors to the present times, where they can encounter the muted, the invisible and the discredited. It can be said that these times and those actors were left behind, but that, through reconstruction and narrative recreation, are put into circulation from the fact of establishing a policy of naming things. "In fact, the past is not something prior to the present but an interior dimension of it. It is not behind but inside."

The consideration of other temporalities, help us to understand that The Other is lived, enunciated, staged and represented, from different rhythms and ways of living to modern issues. In this respect it becomes necessary to understand that there are also other worlds within this world, which depart from the usual model used to establish patterns of behavior, the features that constitute and represent the modern experience. In arriving at this development, we want to emphasize, for example, the "pluriversal", meaning: "other worlds", "denied worlds" and "disadvantaged worlds" but affirmed from their own failure. For this reason, we say that not everything can be reduced to the conception of a temporality cumulative, linear and sequential. We must understand that, outside these conceptions, there are other temporalities like Pachacuti's, "the time that is back", or the philosophy of Ubumtu, "I am because we are." In these forms of establishing meaning, we do not assume the individualization, moved by the work done from efficiency and effectiveness, what stands out here is the community that animates and maintains the shelter that protects everyone. What is indicated in the previous paragraph enters into crisis when the languages that refer to life are replaced and is passed to life that is positioned from the languages that promote ways of living and ways of feeling that are intervened from the logic of capitalism. It is also presented that the way of talking about actors is changed by the ways of the narrative of the authors of texts, or the authors of the speeches. Where descriptions and translations play a central role, thus becoming part of the invention and adaptation of realities to a second reality; we have to say that this has always occurred and corresponds to a situation that warns us about the problem of "naming-knowing related to power".

One of the authors who warned about this situation of naming in relation to knowledge and practices of power was Edward Said, who has already mentioned, wrote a book entitled "Orientalism", 19 where to name is assumed as part of a "collective institution", this is what Orientalism became from the developments that have made Europeans. In the introduction of Said's text are three definitions of what orientalism is, in this case the last definition that this author makes is what interests us at the moment of seeing the situation and need to talk to... and from ...? About this consideration Said says: Orientalism can be described and analyzed as a collective institution that relates to the Orient, a relationship that consists in making statements about the Orient, adopting position on, describing, teaching, colonizing and mentioning the Orient; In short, Orientalism is a Western style that seeks to dominate, restructure, and have authority over the Orient. ${ }^{19}$

The question of reflecting on the prepositions of, in, for, with and from has an importance when dealing with culture in the context of education, as a possible action for the construction of The Other, where reinventions and co-inventions must be present. In this sense, it is not a question of making a "collective institution" that speaks 
for The Other or that acts in the name of The Other, as happened with "Orientalism". All this leads us to ask about the place from which the cultural has been represented, in this case, we have that the culture seen from the confinements that are made to each other, and then typified as unknown, strange, rare, vulgar, abnormal, and dysfunctional.

\section{Ways to name things in education}

We have gone through the experience of facing possible actions in the context of education and school in some places of Colombia, where the key has been the politic of knowledge production, which plays a central role in "localization"12 which we assume as the process of rooting and re-establishment of cultural subjects to their place of birth, residence, transit and encounters from cultural frontiers that travels and come to enrich the experience of cultures. According to Francisco González Cruz ${ }^{20}$ this "tends to satisfy the need for identity, personal and community of the place. Also, the localization has made an appearance in the search of people for rediscovering their own singularity and that of all those with whom it coexists". ${ }^{20}$ The politics of knowledge production would be conceptualized as a dynamic that is based on a practice of positioning staged in a specific context, that is, an intentional action of a substantive nature, where what emerges is located, appropriate, shared and motivated, among other things. This is possible with the transformation of the ways of naming and acting, especially when we assume the discursive frameworks that act in the institutionalization of strategies of integration and legitimating of the ways of saying that people use. According to the approaches that have been developed throughout this text, the idea is to reflect on the place in the representation and representation in the specific place of cultural of semiotic and pedagogical mediations. In order to confront the politics of knowledge production, the action must be assumed as an instance of openness and detachment that favours the generation of possibilities. Hence, we take into account what Paulo Freire proposed "praxis", which is very different from action by the mere fact of action, but rather is the action that leads to mobilization, reflection that leads to the taking of position, where the main purpose is the pursuit for a change. "Critical awareness cannot be reached by intellectual effort alone, but by praxis: by the authentic union of action and reflection; men cannot be prevented from such reflexive action if this were done. Men would be nothing more than active tokens in the hands of leaders who would reserve the right to make decisions" 21

The openness and detachment of the safe forms of representation that occur in contexts is produced from actions motivated to the search of solutions to the problems, the same as it happens with the processes of reproduction that are orchestrated in the education and in the school. An example of this is found in communities where textbooks become an aggressive instance to depose the local culture, and then teachers react by creating their own proposal, their own textual mediations that lead to the generation of a reflection activated from the Fact of valuing the place of the culture in the school from "localization". This originates a policy of knowledge production, where teachers intervene practices of saying in the context of education and school. This leads to what Arturo Escobar has called a "production policy of the place", where the processes begin to generate questions about the practices of subjection and belonging to the territory, here the relationship

\footnotetext{
${ }^{12}$ It is noteworthy that the category of place of origin, in the context of the Spanish-speaking countries, has been addressed by the anthropologist Arturo Escobar, who, from the consideration of the place, comes to raise a series of development that have to do with the organizational processes of the communities Black women in the Colombian Pacific.
}

between: territory, memory and processes of production takes place. Pedagogization that bind the community.

We have to say that education has not always generated possible actions that allow the invention of The Other; this situation has not always been that way, but above all education and school have been operating under the logics of social, cultural and economic reproduction. In this respect, we have the work of Antonio Gramsci, Louis Althusser, Pierre Bourdieu and Michel Foucault, making a sociological analysis of the problems that refer to reproduction from proposals and educational institutions. A case that comes to reflect the reproduction from ways of saying and doing in education and school in Colombia is presented with consideration of linguistic variety and linguistic diversity. Especially when the peoples who have as their mother tongue an ancestral or vernacular language, and also when teaching from monolingual teachers who only speak and act from a pedagogical point of Castilian. In some cases the situation is complicated because it is emphasized that the students must learn a second language, in the Colombian case, the learning of English is widespread, but it is very complicated that in remote regions of the country, where the process of "linguistic revitalization", is needed the government insist on the teaching of a foreign language, when the reality is different and differ from the urban context of the cities of the country. For this reason, we believe that it is necessary to review the way education is conceived, showing how problematic it is to maintain a homogeneous education, in a country that in its constitutional grammar maintains that: "the Colombian state recognizes and protects ethnic diversity And cultural heritage of the nation. ${ }^{13}$

Education has been approached as part of an institutionalized construction, over time this has ensured the production of an order (reproduction). It has also been considered as part of a process that leads when overcoming problems and inequalities, as well as a system that legitimizes the school from state policies. The institutionalization of education as a universal fact starts from mass education, which would serve for the projection of the "emancipatory dream of the Enlightenment" that helped to reach a level of development comparable to the forms of being from the society of central Europe. This happened specifically in French society which has been considered the cradle of modernity, since in this context historical events of rationalism, encyclopaedism and enlightenment were spared, among others.

According to a slope of sociology that considered "education is the institutionalization of socialization" this concept is derived from the commitment of Emil Durkheim in what has to do with the processes of transmission and stability of the contents from one generation to another, is the conception of education "as a basic instrument of social cohesion" that helps to sustain order. This notion of education has developed a way of naming things that affects the field of representation from institutions, scenarios, content and people; therefore, what has been tried is to generate conditions of action for the institutionalization of education, as a project that crosses all types of social organizations.

According to the idea that is being developed, universal education or mass education would be committed to the ideals of illustration to eliminate social distances. All persons, as far as they are equal, have the same right in front of the institutionality of the State that represents the citizens. In this context universal education or mass education, would serve the projection for the attainment of a type of determined subject by modern pretensions; The discourses and

\footnotetext{
${ }^{13}$ Political Constitution of Colombia 1991, article 7, title 1, of the fundamental principles. Presidency of the Republic's Edition.
} 
practices derived from this way of seeing the world, would become the safe place for the enunciation of education. Modernity would become the "historical process that opens with the illustrated project of human emancipation," in which case modernity would be characterized by emancipation, the cult of reason, the progressive nature of history, the circulation of meta-narrative, aesthetics as philosophical discourse, validation of utopias, inductivism-deductivism and the rise of science. One purpose of modernity would be to construct a free and sovereign subject, identified and recognized through the productions of the time that is based on the role of the State and the identity of which it provided to the people; it was a subject-subjected to the institution that established a limit for action.

In the face of this situation, there was (for a long time) the silencing of the ways in which people raised their voices to the concrete experience that made them belong to this world and not outside of it. It was the limitation in the action of those who were not collected by the project of modernity, remaining outside of history, outside of literature and generally outside of any explanation built from the use of Western reasoning; The point of exclusion was so remarkable that in the name of reasoning peoples, communities and cultures, were represented as primitive, aboriginal, "uncivilized" and "uncultured" and basic rights were violated. The cult of Western reasoning led to intervention over being, thinking, doing, and wishing. In a way, it became the new creed built on the ruin of the doctrinal edification characteristic of the middle ages. In fact it was the burial of the faith in God in order to sow faith in reason. In the attainment of the modern subject, education and the school would be a scenario that would guarantee the establishment of disciplined and intervened subjects through the characteristic ways of presenting the project of humanistic domestication of literate modernity. It was related to the achievement of "an integral, original and unified identity" the essence of identity as both the characteristic and the representative of this generalized and projected subject for all humanity. As representative of this situations let us illustrate the case of a third grader child of ethnic origin; the child was characterized by his emotional participations in classes guided by a teacher from the central area the country teaching in the Atlantic Coast. On one occasion the child intervened in class relating the theme the teacher was developing with something from his lived experience and from his own understanding, he tried to extend a bridge between what the teacher said and the way he saw the situation. Suddenly, there was a thunderous expression in the classroom coming from the teacher "shut up, don't you see that what you are saying is irrational, do not say that barbarity, do not mix those things with the things from school". The immediate response of the child was to be silent and not to participate again or speak in class and not only that, since that day the other classmates began to nickname the boy "the irrational."

From situations like those ones, the question is: What is rational and what is irrational? Then, in approaching this question, emerge the need to advocate for a more appropriate language to safeguard children's, joy and fascination with knowledge, to discover and invent other ways of explaining things or situations; whit the purpose of arriving at the answer regardless of the order of the question. All this reflects the problem of reduction and control that are established from the ways of saying things in school and in education setting.

The formation of the wrong-saying of the other and the frames of representation that fix contents

The frames of action in which people are enrolled determine the production of meaning; in this case emergencies of new meanings are produced from the discursive formations that are the best contents to take into account at the moment of reflecting on the silenced, the denied, the invisible and the obliterated. When taking into account The Other as the experience that contains a place of enunciation, it becomes necessary to consider the situation of "not being" which it is invented; it is the denial of autonomy and the right of the excluded. It is the possibility of remaining outside the frameworks of representation, legitimating the actions of those who act according to the experience that is constituted from the lived world and that the case of discourses of prestigious modernity, are not recognized or accepted as representative of human experience. That is why they invented ways of naming and classifying human experience, enclosed within a logic that entails the institutionalization of explanations as representative of a universal truth. Thus the Europeans invented ways of saying where they guaranteed the legitimacy of experiences and they elaborated the projected explanations on the rest of humanity, it was a way of rationalizing the production of experience as both accepted and unaccepted. The formations of the discourses regulating human experience would become the best benchmark for measuring the degree of civilization of peoples. The Europeans would put themselves in the task of enclosing and classifying the experience of other cultures as a historical, abnormal, dysfunctional and irregular; for each situation there would be a model that opposed the other human experiences outside the line of explanation and legitimation of what they were, they came to say that the ideal family model corresponded to the European nuclear family, religion had to be monotheistic, the type of union between couples of different genres had to correspond with the ones of the monogamy and the writing was assumed from their alphabetical spelling because the rest of towns were from a preliterate society.

The education began in the search of a subject formed from the western requirements that saw in the education an "institutionalization of the socialization", therefore, this form of assuming the education led to cultivate customs that were projected on the rest of the humanity. It was the destiny of mankind, while generalized intention of formation corresponded to the ideal of progress in the midst of an ideal consideration of equality of persons, against greatest inequalities that have occurred throughout the history of the West and its prolonged discursive. The consideration of education as a form of modeling that guarantees the action-legitimation or delegitimation of the ways of saying that circulate through the particular scenarios of socialization of people. When an evaluation of the results of education and school is made, the scope of the evaluation must be determined as a project of reproduction, classification or transformation, all three possibilities lead one to think that the function of education and school identify according to the purpose of training that relate to social, political, economic and cultural conditions. For a time, education and the school as a project of homogenization for the achievement of a generalized identity from the modern project has generated a certain physical and epistemic violence, characteristic of the fact of starting from the place where the discourses are originated or are in the place of specific experience of the people who represent the world from the reference to the place or position they have to produce speeches. But, that for the sake of Western reason the possible relational emergencies of the world of culture are muted and violated as something from diversity rather than something unique.

In order to generate a view of the discursive production frameworks that act as guarantors in the validation of the discursive experience of the people in the field of education, it is necessary to look at some ways of saying that have contributed to expatriation of territory of the actors whom should represent their culture from the world of the 
culture in which they lived or where they are situated; this is the result of the regulation of education from the point of view of government of mainstream society, where overtime they have been privileged with universals way of saying and represent concepts which have led to neglect and devaluate the practices of the local citizens in their located practices and representation involving concrete actors. In this case we can take a look at the experience of the education of the ethnic groups that can be seen as The Other, but in reality they have been silenced and dislodged from any possibility of representation, when it is understood that the place of culture is within the configuration of a self-thought. As examples of the situation of silencing of the components of the context in the context of education, we want to take three cases, the first is related to the natives of the Sierra Nevada de Santa Marta in northern Colombia, specifically with the Ikus or Arhuacos, The second with black or Afro-Colombian communities and the third is the case of a visually impaired student. The three cases lead us to reflect on the necessity of possible actions from the fact of facing the mispronunciation or the inappropriate way of saying things ignoring how others cultures associate with it. Here the saying, compromises an act that is associated with the depersonalization and the discredit of the people who are usually represented as inferior beings.

At a certain time during the visits we made to the Arhuaco ${ }^{14}$ people of Nabusimake in the department of Cesar in northern Colombia; we witness the case of indigenous children who went to school to learn contents that discredited the world of their lived culture which they learned through the ways of saying from their authority "The Mamo", ${ }^{15}$ Is the opposition between the ways of learning the lived world of culture through socialization, in opposition to the ways of learning when the information transmitted by the teachers of the school. During our visit, the school teacher (who was formed and belonging to the Western worldview) was lecturing about natural science and more specifically the subject was about stones, he mention to the indigenous children that stones were inert beings who had no life. Then, a child intervenes saying "and why the Mamo says when we are in the Kankurua ${ }^{16}$ that the stones have life, power, give life and have energy that are good for pagan. ${ }^{17}$ "After the intervention of the Arhuaco child, the teacher affirmed "those things that the Mamo says are myths and legends, those things cannot be verified as we verify science facts that are true and objective."

The previous example demonstrates the impossibility of a dialogue of intercultural knowledge, taking into account: respect, acceptance, recognition and appreciation of other's knowledge, which should not only be taken for their evicted and devalued thinking of modern society. What is at stake is the possibility of deepening the differences that happen to be a relevant aspect in the recognition of diversity and the construction of alternate circumstances that allow reference to the constituent of the ways of saying from the perspectives of "them", "us" and "others". In this experience, appears the mispronunciation or the inappropriate saying of the others' ways of saying, because

\footnotetext{
${ }^{14}$ Part of the 86 indigenous peoples of Colombia, belonging to the Chibcha linguistic family.

${ }^{15} \mathrm{He}$ represents the traditional authority of the wise man and the shaman.

${ }^{16}$ Ceremonial site or place, deep spiritual connotations of the indigenous people Iku or Arhuaco.

${ }^{17}$ The payment ritual, is the act performed by the Indians to pay and repay the benefits received from nature to it; Seeking in this way to achieve a balance in all aspects, physical, spiritual, energetic, etc.
}

they do not speak for themselves in a world where the discursive conditions of production are controlled. Another example that reflects the problems that are being addressed is related to a group of AfroColombian children attending a district education institution; the families of these children have been displaced from their territories as a result of the armed conflict that still persists with less intensity In Colombia. Already in the district school that they attend the teacher keeps saying that "they talk too much and they are not quiet, they are messed up when it comes to writing ... The whole problem of indiscipline in the room is because they are not quiet in their seats and they keep talking, I will sew their mouths so they won speak ...’The teacher does not take into account the particularities of the context in which they have been socialized not to mention they are displaced children, they are children from one of the shores where oral tradition is constituted as a fundamental element for the construction of the cultural being; differentiated with respect of generalized forms of representing and disciplining the body in the Western school through writing as an imposition. In this example, the negative role played by misinterpretation, where the bodies of the different ones, are named from a state of abnormality, that is to say that they are where the very thing is to disqualify the forms of being in a body that is perceived as part of a threat that has to be appeased and for this there is education and school.

The last case is that of a university student who enters a class where a topic about identity is developed, as a strategy the teacher uses an audio-visual text that is subtitled, in the session in which the film is presented; the teacher and the classmates take into account that the student has visual limitation and as a result of this situation the teacher in the following session alludes to the film considering the young student and says" well in the following movie I will ensure that it is translated to Spanish so that our class mate can participate". The young student tells us about the situation she has to go through when she is lining up to take food in the students' cafeteria. "I have to do the normal line up and that's very uncomfortable for what it means ... sometimes people are not aware of my situation and they do not care about me and as I am not used to these things because I am not from this area which makes things more difficult for me. Finally, we have expose the approach of how knowledge is being perceived in a global concept through the cases presented as an example and, showing how The Other has been interpreted in the field of education, where the frameworks of action are established based on assumptions that direct the ways of relating people. In this case prejudices, stigmatizations and stereotypes, come to play a central role in arranging and supplanting the existence of people, where invisibility, ignorance, silencing and denial of others are invented as "abnormal", "uncultured", "racialized" and "backward" beings. With the possible actions that involve all of them as a whole, it is sought to overcome or better face these situations of domination and marginalization that produce "social death" of children in school. ${ }^{22}$

\section{Acknowledgments}

None.

\section{Funding}

None.

\section{Conflicts of interest}

Authors declare that there is no conflict of interest. 


\section{References}

1. Grimson A. Interculturalism and communication. Bogotá: Norma; 2000

2. Restrepo E. Contemporary Theories of Ethnicity. Popayán: Universidad del Cauca; 2004.

3. Freire P. Pedagogy of the Oppressed. México: DF Siglo XXI; 2010.

4. Martín Barbero J. Education from communication. Bogotá: Norma; 2001

5. Hall S. Sin garantías. Without guarantees- trajectories and problems in cultural studies. Colombia: Universidad Del Cauca; 2014.

6. Spivak CG. Can the subordinate speak? Revista colombiana de antropología. 2003;39.

7. Baudrillard J. Cultura y simulacro. Barcelona: Kairós, Simulacra and Simulation; 1978.

8. Vich V, Zavala V. Orality and power. Bogotá: Editorial, Norma; 2004.

9. Moreno FM. Principles of sociolinguistics and sociology of language. Barcelona; 1998.

10. Burke P. Visto y no visto. Barcelona: Crítica, Eyewitnessing; 2001.

11. Walsh C, Schiwy F, Castro-Gómez S. Decolonial pedagogies. Quito: Abya Yala; 2013.
12. Giroux H. Border Crossings. Barcelona: Paidós; 1997.

13. Walsh C, Schiwy F, Castro-Gómez S. Indiscipline in social sciences. Quito: Abya Yala; 2002.

14. Santos SSB. An epistemology of the South. México. Siglo XXI; 2009.

15. Nina F. Black Studies in Colombian Anthropology: Presence and Invisibility. 1984.

16. Mignolo W. Cambiando las éticas y las políticas del conocimiento: Lógica de la colonialidad y postcolonialidad imperial. Bogotá: Revista Tabula Rasa, número 3, Universidad Colegio Mayor de Cundinamarca; 2005 .

17. Gómez RF. Literary language. EDAFSA. 1994.

18. Vasilachis I. Qualitative research strategy. Buenos Aires: Gedisa; 2006.

19. Said E. Orientalism. Barcelona; 2004.

20. González CF. Globalization. Mérida: Fondo Editorial Universidad del Valle de Momboy; 2013.

21. Freire P. Concientización. Bogotá: Asociación de publicaciones Educativas; 1972.

22. Vich V, Zavala V. Cultural Studies. Lima: Universidad del Pacífico; 2001 . 